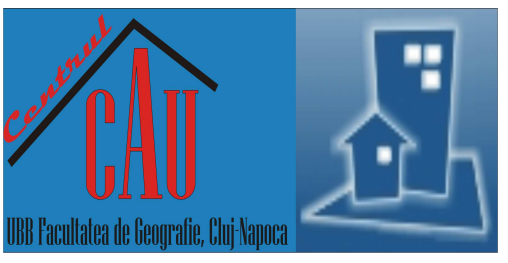

\title{
Regional Landscape Planning and Local Planning. Insights from the Italian Context
}

\author{
Anna Maria COLAVITTI ${ }^{*}$, Sergio SERRA ${ }^{1}$ \\ * Corresponding author \\ 1 University of Cagliari, Department of Civil and Environmental Engineering and Architecture, Cagliari, ITALY \\ $\triangle$ amcolavt@unica.it (D) https://orcid.org/oooo-0oo2-0484-3131 \\ $\triangle$ sergioserra@unica.it (D) https://orcid.org/oooo-0oo2-2828-7360 \\ DOI: 10.24193/JSSPSI.2021.7.07 \\ https://doi.org/10.24193/JSSPSI.2021.7.07
}

$\mathbf{K} \mathbf{e} \mathbf{y} \mathbf{w} \mathbf{O} \mathbf{d}$ s: regional landscape planning, urban and territorial planning, cultural heritage, participation, territorial governance, multilevel governance, inter-institutional cooperation, integrated planning

\begin{abstract}
A B S T RACT
Landscape has acquired great importance in the urban and territorial policies of European countries after the European Landscape Convention. Italy has a long tradition in the protection of landscape and cultural heritage, characterised by a particular attention to the history and the identity culture of the communities. The main rule in this field, the Code of Cultural Heritage and Landscape of 2004 (Urbani Code), refers to a mix of environmental, cultural, and social factors belonging to different types of natural and urban landscapes that Regional Landscape Plans have to identify, sharing with local communities. The most important innovation concerns the attempt to overcome the binding and regulatory approach, only focused on protection constraints, in order to generate high awareness about the identity value of landscape and to encourage a more democratic community participation in the landscape policies. The ineffectiveness of landscape policies is often due to the lack of sharing of the landscape vision and planning approaches established at regional level, with local authorities and settled communities. This paper reflects on the topic of inter-institutional collaboration between national, regional, and local authorities, by focusing on the process of adaptation of urban local plans to the regional landscape plans and comparing different regional contexts. The article highlights a strong delay in the approval of regional landscape plans and a relevant inter-institutional conflict in the co-planning phase with the national authority, leading to the ineffectiveness of landscape plans in the transfer of regional landscape planning guidelines to the local landscape scale, with relevant consequences on territorial government, between conservative measures and transformation drivers.
\end{abstract}

\section{INTRODUCTION}

The protection of landscape and national cultural heritage is a key concept of the Italian Constitution, clearly expressed in the article 9, which guarantees the integrated application on different territorial levels. The long legislative tradition in the field, from the Bottai Laws of 1939 to the Galasso Law of 1985, has been integrated in the Code of Cultural Heritage and Landscape of 2004. The European
Landscape Convention of 2000 (ELC) identifies the landscape as "the territory expressive of identity, whose character comes from the action of natural and human factors and their interactions" (Art. 131, Legislative Decree 42/2004). The Urbani Code encourages a vision of landscape strongly connected to the history and expression of the culture and the identity of the communities. In the international context prevails an idea of landscape strongly integrated with the nature and the environment. Instead, in Italy, the disciplinary 
approach and the normative framework focus on the cultural dimension rather than on the ecological one. This is mainly due to the peculiarities of the Italian territory, which result from long processes of territorialisation and anthropization that have produced a continuous stratification of alterations and human interventions on the environmental system. For this reason, the landscape acquires a strong cultural character, in which also the natural parts of high ecological value represent the product of the interaction between man and nature.

The close relationship that joins the environmental and historical-cultural heritage to the landscape is well outlined in the Urbani Code. It also introduces relevant innovations concerning landscape planning and the system of constraints (Cartei, 2008; Settis, 2010). In particular, it establishes the centrality of landscape planning in the territorial government, with the task of defining the statutes of the territory and the modalities of use and transformation of the local assets, according to a multidisciplinary approach.

The principles outlined by this law led to a season of renewal in the field of territorial planning, trying to improve the analytical and interpretative apparatus of the specific system of territorial values (Trusiani, 2015). The Regional Landscape Plan (RLP) is the instrument designed to identify the territorial invariants to be subjected to measures of conservation and enhancement, according to the so-called "active preservation". This approach is differently interpreted by the regional landscape plans and transferred into specific directives and prescriptions by local planning, which often do not take into account the real needs and demands expressed by the settled communities.

The elaboration of the landscape plan must be carried out jointly by the Ministry of Culture (MiC) of the Italian government and the regional authorities at least for the landscape assets represented by properties of relevant public interest (already protected by law no. 1497 of 1939), areas protected by law (according to Galasso law no. 431 of 1985) and further properties and areas that are specifically identified and subject to the protection of landscape plans. Originally the Code referred to further assets categorized by the RLP, concerning specific peculiarities and values of the local identity. Nowadays the possibility for local authorities to identify further assets is referred to certain categories already protected by law.

Several revisions of the Code have underlined the attempt to limit the RLP authority to the management of the landscape assets, already recognised and declared as such by the legislation, neglecting the complexity of the landscape dimension and the importance of a wide recognition of the values to be protected.

The joint drafting of landscape plans by the State and the Regions can be regulated through the 82 signing of special agreements, which also establish the deadlines for finalising the instrument (Art. 143, Legislative Decree 42/2004).

The national government and the regional authorities ensure that the whole territory is adequately known, protected, and managed according to the different values expressed by each context of reference, identifying the areas characterized by homogeneous and distinctive landscape features and providing a set of rules and actions for the achievement of specific quality objectives (Art. 135, Legislative Decree 42/2004).

The landscape plan is not limited to apply the legal instruments and tool of constraint, aimed exclusively at the preservation of the invariants. It also follows programmatic and planning objectives of territorial transformation that are traditionally assigned to the competence of the local administrations (Cartei, 2008).

The landscape plan can develop guidelines for projects of conservation, recovery, redevelopment, enhancement, and management of some regional contexts, indicating the most adequate tools and incentives for their realization. The landscape plan is superordinate with respect to local planning and therefore, from the date of approval, the relative prescriptions are immediately binding and prevail over the provisions of territorial and urban plans.

The Urbani Code requires a collaboration essentially limited to two public bodies, the Ministry and the regional administrations, in the definition of guidelines and criteria for the protection, valorisation and management of landscape assets. The territorial administrations have the task of conforming their planning activities to the criteria defined by the superordinate plan and, in the short-term, to the adaptation of urban plans on a local scale (Art. 133, Legislative Decree 42/2004).

In some cases, the adaptation of municipal urban plans to the RLP allows the exception to the landscape authorization for interventions concerning protected areas, which are not of relevant public interest, or for interventions on highly compromised or degraded areas designated by the plan.

On one hand, the role of the municipal authorities could appear marginal in the landscape policies but, in truth, the adaptation of local planning tools is essential for the achievement of the landscape quality objectives. The ineffectiveness of landscape policies is often due to the lack of sharing of the landscape vision and planning approaches, established at regional level, with local authorities and settled communities.

This paper reflects on the topic of interinstitutional collaboration between national, regional, and local authorities, focusing on the methods for transferring the guidelines and strategies of the RLP into the provincial and municipal urban planning, at 
both general and operational levels. The main research goal is to evaluate the degree of implementation of regional landscape planning in relation to the process of adaptation of municipal plans, pointing out the similarities and the differences of each regional context.

The research outcomes are summarized in a comparative overview of landscape planning in Italy which shows a strong delay in the approval of regional plans and a relevant inter-institutional conflict in the co-planning phase with the Ministry. The conclusive reflections lead to the discussion of the effectiveness of landscape plans in transferring the planning guidelines to the local scale, with relevant consequences in the territorial government between conservative measures and transformation drivers.

\section{THEORY AND METHODOLOGY}

The paper analyses the state of progress of the process of elaboration and approval of the landscape plans as it emerges from the analysis of the scarce literature on the subject, in an attempt to highlight those that have been definitively approved and are compliant with the Urbani Code. The research then continues with the study of the process of adaptation of local plans to the RLP, trying to highlight some fundamental problems inherent in the administrative process by which plans are approved, but above all problems related to the value content of the way in which local communities adapt their urban planning instrument.

The methodology is the comparative analysis of the Regional landscape plans. To do this, our research has deepened the official documents available in the institutional websites, in particular the technical regulations and the illustrative report. In order to define a brief overview of the different regional approaches to landscape planning, we investigated the following issues:

- the role of landscape planning in the territorial governance and the coherence with the national legislative framework and with the main principles expressed by the European Landscape Convention;

- the inter-institutional cooperation for the drafting of the landscape plan, the emerging conflicts and the effectiveness of the co-planning procedures;

- the involvement of settled communities in the planning process, from the recognition of the identity values to the definition of shared strategies for the protection and enhancement of the territorial assets;

- the methods of integration and coordination in the landscape, territorial and urban planning processes;

- the methods used to implement landscape plans, with the distinction between direct and indirect prescriptions, constraints, levels of legal obligation and guidelines for local planning;

- the process of adaptation of local planning tools to the RLP, in terms of procedures, timing and progress status;

- the restrictions and limits to territorial transformations in the transitional phase, until the adaptation of local plans to the superordinate instrument.

\section{RESULTS AND DISCUSSION}

\subsection{The framework of landscape planning in Italy}

The progress status of the landscape planning process is rather heterogeneous in the different Italian regions, as shown by the overview made available by MiC, updated to December 2020. Before the Urbani Code came into force in 2004, most Italian regions already had a regional landscape plan covering the whole territory or a well-defined part of it, except for Calabria and Friuli Venezia Giulia.

Today, the number of regional landscape plans (RLP) or regional territorial plans (RTP) with landscape value or regional territorial landscape plans (RTLP), that have been approved in compliance with the Urbani Code, is still limited (Fig. 1).

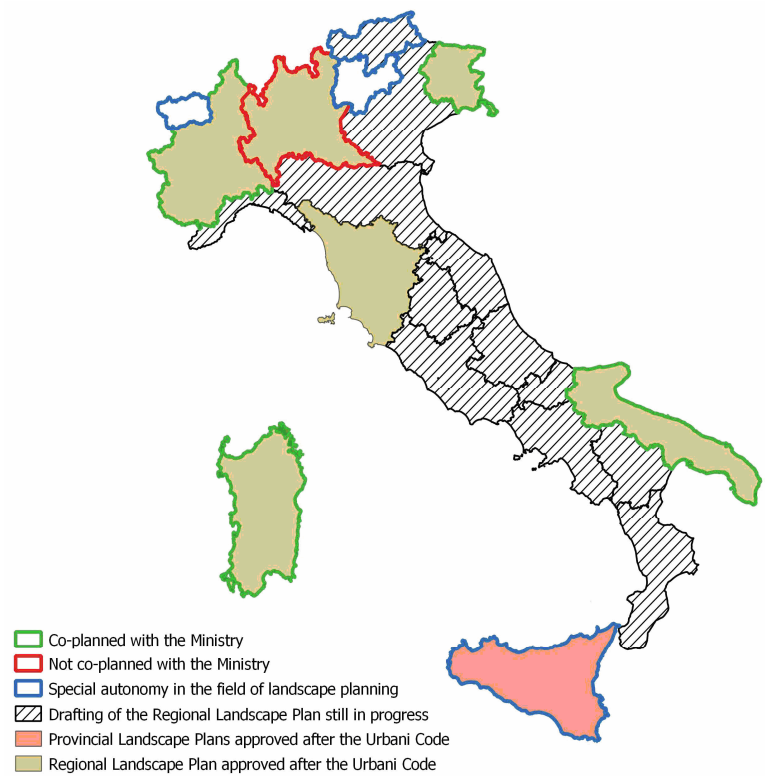

Fig. 1. The framework of the regional landscape planning in Italy (source: authors' elaboration).

Following a chronological order, we list: the RLP of Sardinia, approved in 2006 and limited to coastal areas; the RTLP of Apulia and the RTP with landscape value of Tuscany, both approved in 2015; the RLP of Piedmont in 2017 and the RLP of Friuli Venezia Giulia in 2018. In addition, there is the RLP of Lombardy, approved in 2010, without co-planning with the Ministry for Culture (MiC). 
In other cases, the inter-institutional conflict emerges clearly in cases of decisions taken unilaterally by regional authorities, for example in the Regional Landscape Territorial Plan (RLTP) of Lazio, approved in 2019 by the Region without considering the previous work and decisions shared at the joint technical table with the Ministry. For this reason, the Council of Ministers, as required by $\mathrm{MiC}$, has appealed to the Constitutional Court against the Region for conflict of attribution, leading to the cancellation of the approval of the RLTP in October 2020.

Also in the case of the Veneto Region, the process of joint elaboration of a RTP with landscape value has not followed a linear course: after the signing of an agreement in 2009, in the same year a partial amendment of the RTP was adopted in order to attribute the landscape value, leading to the approval of the plan without landscape value in 2020. Discussions are currently underway between the Region and $\mathrm{MiC}$ for the updating of the agreement on the joint drafting of a RLP which is separate from the RTP but recovering the co-planning activity carried out until now.

Some regions with a special statute have been granted a certain degree of autonomy in landscape matters, which allows them to use different tools and methods and to avoid the mandatory co-planning with the MiC (Valle d'Aosta, Trentino Alto Adige, and Sicily). Valle d'Aosta has a Landscape Territorial Plan on a regional scale, prior to the approval of the Urbani Code. Friuli Venezia Giulia has defined landscape planning tools on different levels, from the provincial dimension for the Province of Trento to the municipal scale for the Province of Bolzano.

Sicily has approved landscape plans on a provincial scale, in compliance with the Urbani Code. The other regions (Liguria, Emilia Romagna, Umbria, Marche, Abruzzo, Molise, Basilicata, and Calabria) have signed a protocol of agreement with $\mathrm{MiC}$ for the joint drafting of the plan, which is still in progress. The Campania Region, on the other hand, approved a preliminary RLP in 2019, which is waiting to be completed in the drafting and approval procedure. Only six regions that have approved their RLP after the Urbani Code are investigated in this article.

\subsection{The Regional Landscape Plan of Sardinia}

In 2006, the Region of Sardinia approved the first landscape plan in Italy in compliance with the Urbani Code, which was anticipated by the introduction of some temporary rules aimed at the protection of the coastal zone (Bitti, 2008; Ercolini and Morelli, 2010).

The law on coastal protection, R.L. n. 8/2004, provided for the approval of the landscape plan within one year from its entry into force and imposed a building restriction in a buffer zone of two kilometres from the shoreline. The main objective was to avoid the 84 damage of the coastal heritage in the period before the adoption of the new regional plan.

The RLP focuses the analytical apparatus and the strategic vision on the coastal strip, which includes about $41 \%$ of the regional territory, where it identifies 27 landscape areas, with homogeneous landscape features and subject to a specific regulation.

Toward an active conservation of the landscape, local authorities are required to identify, in the general plans, the "local areas for landscape design", characterized by homogeneous components and repositories of material and immaterial values resulting from the sense of belonging of the community to the places (Cartei, 2008).

The plan aims to preserve, valorise and hand down to future generations the environmental, historical, cultural and settlement identity of the territory. Landscape is conceived as a complex system of heterogeneous components, complementary and interdependent, in continuous evolution. Therefore, the landscape project must interpret the relationships between the various components of the local identity and elaborate scenarios of conservation and compatible transformation (Campus and Ercolini, 2011).

The RLP establishes the criteria for the identification of the landscape values, without submitting them to an adequate activity of public participation, strongly reduced due to the time constraints for the plan drafting (Colavitti, Serra and Usai, 2018). The cognitive framework integrates the knowledge of different disciplines that contribute to the definition of the "statute of the territory", according to three territorial assets (environmental, historical and cultural, settlement) (Colavitti, 2018; Vettori, 2017).

The RLP contents have a descriptive, prescriptive, and propositional character. They provide guidelines and prescriptions for the conservation and maintenance of the most significant features of the landscape and define the actions and the territorial transformations in a perspective of sustainable development.

The provisions of the RLP are mandatory for local authorities and immediately prevail over any different and less restrictive provisions contained in the municipal plans and in other sectorial planning acts with spatial impact. In any case, the identified landscape and identity assets are subject to the discipline of the RLP, regardless of their location. The other provisions of the RLP are immediately effective for the municipalities totally or partially included in the coastal landscape areas.

The RLP is designed to restore a framework of certain and fair rules and to remove any kind of arbitrariness and excessive discretion both for the Region and for local authorities. During the adaptation of the urban general plan, the municipalities have the possibility to extend and integrate the collection of 
environmental, landscape and historical-cultural values, based on a detailed territorial knowledge, and to integrate the strategies for their valorisation.

The RLP provisions can be implemented with the adaptation of provincial, municipal, and sectorial planning, also through agreements between the Region, Provinces and municipalities involved in the definition of strategic actions of urban recovery and territorial transformation, based on objectives of landscape quality. The Sardinian RLP has adopted a temporary regulation that is particularly restrictive for the coastal landscape areas, until the adaptation of the municipal urban plans.

In particular, for those costal municipalities without a municipal urban plan in line with the RLP, building activities are allowed only in the urbanised area and in the development areas close to that already urbanized and surrounded by geographic, infrastructural and settlement elements, if scheduled in the executive plan in force at the date of the RLP adoption.

The system of constraints, applied during the transitory period, strongly limits territorial transformations in the municipalities that are totally included in the coastal landscape areas (102 municipalities of the total 377), which are subject to compulsory adjustment of the general plan, within one year from the entry into force of the RLP. For those municipalities not included in the coastal landscape areas (210 municipalities) or only partially included (65 municipalities), the adaptation is only optional until the extension of the RLP to the inner areas, which has not yet been developed.

\subsection{The Regional Landscape Plan of Lombardy}

The 2010 Landscape Plan of Lombardy is part of the Regional Territorial Plan, interesting the whole regional territory. Since 2016, a revision of the plan has been ongoing, with the aim to increase the effectiveness of regulatory tools in the processes of planning and design at the local scale (Arcidiacono, Fior and Pasqui, 2016).

The plan recognises the widespread presence of landscape values, not only in the areas subject to specific landscape protection, but also in the other parts of the regional territory. The framework of actions and prescriptions of the plan has three main goals: the preservation of the characters that define the identity and the recognizability of the regional landscapes, through the control of the processes of territorial transformation; the promotion of the landscape and architectural quality; the diffusion of the awareness of the landscape values and their fruition by the citizens.

The plan is structured into three fundamental sections (knowledge, normative and programmatic) and carries out the double function of Landscape Reference
Framework and normative tool, which is valid until more detailed landscape acts come into force.

The landscape discipline of the RLP, in accordance with the principles of subsidiarity and competence of other institutions, addresses the territorial transformations to the protection of the distinctive features of the different typologies of landscape units. Also, it provides general prescriptions for the landscape assets and immediately effective provisions on contexts of landscape and environmental relevance, specifically identified and delimited by the plan. During the adjustment or drafting of municipal plans, local authorities must verify and, if necessary, modify the perimeters of these areas, elaborating an indepth study and an adequate regulation, according to criteria and guidelines defined by the RLP. According to the Urbani Code, the norms of the RLP are immediately prevalent over the other more detailed acts of landscape value that are in contrast with them.

The municipalities, that fall entirely or partially within the areas of relevant landscape value and high naturalness (e.g. the Lombard lakes), have to revise their urban planning tools in accordance with the objectives, the regulation and the particular provisions of the RLP. Meanwhile, urban planning and building interventions cannot be carried out, except for interventions in urbanised areas, including enclosed lots and excluding the undeveloped fringe areas, delimited by municipalities, or in the case of acquired rights for the realization of development projects already approved or funded by public authorities. Until the adaptation of the general plan, all the development plans not yet adopted are anyway stopped if they are not specifically designed for the requalification of existing urbanized areas.

In the areas that are not subject to specific landscape protection, the RLP provides the opportunity to define the level of landscape impact for projects that affect the aesthetic of the place and buildings, evaluated initially by the applicant and then by the institution in charge of the release of construction permits.

Municipal planning defines measures and actions to safeguard and promote the recovery of the historic centres and traditional rural settlements, in accordance with the specific identity characteristics related to the historical and architectural aspects and the relative context.

During the revision of their planning instruments, the municipalities verify the perimeters of the historical centres and settlements and adapt the urban planning regulation to the provisions and guidelines defined by the RLP. Another contribution is given to the realization of the regional green network by defining the system of municipal green in their urban plans and, in particular, through the identification of ecological corridors that connect rural and urban areas. The current revision has become necessary due to the 
limited effectiveness of the RLP in the governance of landscape policies at the provincial and municipal level. The provincial plans have often elaborated targeted indepth studies and project proposals with different approaches that are not always coherent with other contexts referred to the same landscape system. The local outcomes have been even more disappointing, where planning tools have often limited themselves to reproposing the superordinate provisions without integrating them into the system of objectives and actions of the plan, with extremely limited results in terms of territorial transformations (Arcidiacono, Fior and Pasqui, 2016).

\subsection{The Territorial Plan with Landscape Value of the Tuscany Region}

In 2015, the Region of Tuscany approved the Territorial Plan with landscape value, promoting a sustainable and durable socio-economic development and a responsible use of the territory. It aims to preserve and recover all aspects and characteristics that are distinctive of the social, cultural, manufacturing, agricultural and environmental identity of the territory.

The discipline of the RTP is organized in two parts: the first concerns the statute of the territory, which is made up of rules for structural invariants, for landscape areas and for landscape assets and constitutes the integration of the landscape in the plan; the second outlines the strategy of territorial development.

The statute of the territory recognizes the landscape heritage and the structural invariants as assets to be protected and enhanced, conceived as longterm structures produced by the coevolution between the natural environment and human settlements, recognizing their value for present and future generations (Marson, 2016).

The territorial heritage, composed of different elements and structures (hydro-geomorphological, ecosystemic, settlement of historical-territorial and identity value, agro-forestry), represents a common good that needs to ensure the conditions of reproduction, sustainable uses, and durability.

The general principles of the RTP are based on the need to correlate the dynamism of private economic enterprise (necessary to ensure the soundness of the productive economic system and, in general, the financial sustainability of the system), social functionality (linked to a system of inclusive welfare for settled communities) and environmental functionality (necessary for the active conservation of the natural and historical heritage).

In order to achieve the objectives of the RTP, in the drafting of the territorial government documents, the Region and the competent local authorities refer to the policy guidelines, apply the directives and comply 86 with the prescriptions specified in the regulations of the statute of the territory.

The RTP classifies the structural invariants, articulated into morphotypes based on the characteristics, values, and criticalities. It also provides guidelines and regulations to the intervention to each morphotype contextualized in the area schedules. They represent a technical-operational reference in the elaboration of the territorial and urban planning. Local authorities contribute to implement the cognitive and interpretative framework of the several plan documents (for example, they identify the perimeter of the urbanized area) and to define landscape projects, ensuring the mutual coherence between sectorial policies and territorial regulation. The method of monitoring was indicated in the landscape observatory. It should help to overcome the conflict related to the culture of the restriction, in the relationship between State and local authorities.

\subsection{The Apulia Regional Territorial Landscape Plan}

The regulatory provisions of the RTLP of Apulia, approved in 2015, are organized into: general and specific objectives that the actors should achieve; directives, which define methods and conditions to ensure the realization of the objectives through appropriate planning and programming tools, thus resulting mandatory in the adjustment of municipal plans; prescriptions, regulations to conform the juridical system of landscape assets, aimed at regulating the admissible uses and the allowed transformations; guidelines, which orient tools or interventions of particular importance (Albrecht, Barbanente and Monno, 2020).

Also in the case of Apulia, the discipline of the plan has different levels of compliance. The prescriptions are binding rules, immediately effective, prevailing over any incompatible provisions of the local planning in force. On the other hand, the guidelines consist of recommendations and methodological criteria for the drafting of local plans and programs.

The RTLP promotes the use of the co-planning method, in which the proceeding administration involves the Ministry (in case of protected landscape assets), the Region and any other public and private subjects involved. This is a form of cooperation and consultation between the different actors involved in the planning activities or in the programs related to the protection and enhancement of the landscape. In this way the provisions of the RTLP become compulsory for urban planning instruments and sectorial regulations, without replacing any authorization or other acts of control established by national and regional laws.

The Region and the other territorial authorities encourage the signing of agreement 
protocols for the definition of common and coherent policies for the conservation and valorisation of the landscape. The substantial uniformity of the natural, environmental and landscape values or the strict integration and interdependence of the settlement, economic and social structures require the assumption of specific commitments by the several actors involved in programme agreements, local territorial pacts, or other forms of governance (Martinelli and D'Onghia, 2020).

The processes of municipal plans adaptation should have been completed within one year after the entry into force of the RTLP but, at present, less than $7 \%$ of municipalities have conformed their urban planning instrument to the RTLP. The approach of the Tuscan and Apulian plans is similar for the knowledge framework. The method of co-planning and participation, in the case study of Puglia, is based on a regional law, R. L. n. 20/2009, that deals with the social production of the landscape.

\subsection{The Piedmont Regional Landscape Plan}

The RLP of Piedmont approved in 2017 subdivides the whole regional territory into 76 landscape areas, further articulated in 535 sub-units. They are subject to specific rules for their use and valorisation, through a normative framework composed of guidelines, directives, general and specific prescriptions for the use of landscape assets, as well as landscape quality objectives. Guidelines are substantiated in indicative provisions and criteria for sectorial, territorial, and urban planning at different levels. Responsible authorities can exercise a motivated discretion in the modalities of reception, although in accordance with the RLP objectives.

Instead, directives are considered as mandatory provisions to be transposed in the elaboration of sectoral, territorial, and urban plans, allowing any exceptions only if adequately justified and technically supported.

General and specific prescriptions of use are considered binding and overriding rules, with direct conformative effect on the legal status of landscape assets included in the RLP, which regulate the allowed uses and transformations.

Prescriptions can impose mandatory restrictions on the use of public and private property rights, not subject to compensation. The rules contained in the RLP are complementary to each other and, in case of different conditions, the more restrictive ones prevail.

The provisions of the RLP constitute the reference framework for the protection and valorisation of the regional landscape, coordinating and addressing the territorial, urban, and sectoral planning. The planning tools at different levels must ensure the consistency of all transformative actions with the provisions of the RLP. Urban plans are therefore checked for conformity within twelve months of approval of the RLP, which may require adjustment. The Region may provide additional tools to support the successful implementation of the RLP, such as guidelines, manuals, and catalogues of best practices on specific issues.

Until the check or adaptation of the subordinate territorial and urban plans, their provisions are applied, if not in contrast with the RLP prescriptions. Municipal and other territorial plans may contain more restrictive rules for the environmental and landscape protection. In the process of adaptation to the RLP, the provincial and local plans can specify, supported by detailed analysis, the cartographic data of the landscape plan, as well as provide for the recognition of any additional components to be protected and enhanced, by sharing choices with the Ministry and the Region.

The cartography assumes a prescriptive value for the application of the binding and immediately prevailing provisions, although, in case of inconsistency between normative and cartography, the first ones prevail. The Region updates the database and periodically revises the RLP according to the adjustments made to the provincial and local tools and to the new cognitive elements that emerge as a result of specific investigations carried out by the Region itself. The role of the provinces and of the metropolitan city is mainly aimed at guaranteeing the achievement of the landscape quality objectives at a supra-municipal level. The role of individual or associated municipalities is carried out in compliance with the legislative attributions about landscape assets. It is mainly aimed at the protection, safeguarding and enhancement of the landscape peculiarities and the requalification of the territories under their jurisdiction, in relation to the level of detail of their own planning instruments, constituting the reference for in-depth studies on the urban and architectural scale of the RLP topics.

\subsection{The Friuli Venezia Giulia Regional Landscape Plan}

The RLP of Friuli Venezia Giulia, approved in 2018, investigates and describes the whole regional territory, through the identification of homogeneous landscape areas. It expresses mandatory prescriptions only for those parts with significant identity and landscape values. The plan is composed of the following parts: statutory, which includes the contents of the Urbani Code and deals with landscape assets; strategic, with further details than those provided by the Urbani Code aimed at directing the transformation of the landscape based on cultural and ecological values and to integrate the landscape in other policies; 
management, oriented to the definition of operational and monitoring tools.

The discipline of the RLP assumes different effectiveness for the landscape assets (binding prescriptions of use), for the other contexts referred to in Article 143 paragraph 1, letter e) of the Code (measures of protection and use) and for the other parts of the territory (guidelines and directives). The prescriptions of use concern the landscape assets, for which the Code recognizes the landscape and cultural value. They regulate the admissible uses and the allowed transformations through a binding discipline, immediately mandatory and prevailing on the incompatible provisions of any plan or program in force.

Guidelines and directives set out the criteria to integrate the landscape in the policies of territorial government and define the modalities to guarantee the realization of the RLP objectives, to be implemented in the territorial, urban, and sectorial plans according to the established modalities and times.

The landscape plan is immediately binding for the purposes of the conformation of urban tools. The territorial authority, except for landscape assets, has the right to apply a motivated discretionality in the implementation of guidelines and directives, in coherence with the objectives identified by the RLP, also taking into account the outcomes of participatory processes and specific local situations.

The RLP makes choices that are in line with the law (i.e. the minimum contents of the plan defined by the Code) while, at the same time, it selects only those assets and aspects that can be governed by landscape planning. The RLP identifies "other contexts" different from landscape assets (i.e. categories of assets that are important for the landscape quality and express the identity value of the territory in which they fall) to be subject to specific measures of protection and use. The interventions in these areas do not require landscape authorization, but the conformity to the RLP is verified within the procedure of concession of the building licence.

In summary, based on an adequate analysis of landscape characteristics of the territory, the RLP identifies the different areas and establishes, for each of them, the landscape quality objectives, and the guidelines for urban and territorial planning. It also carries out the recognition of all landscape assets, identifying them cartographically and defining prescriptions for their protection and valorisation. It identifies other contexts, different from landscape assets, but with a value that requires specific prescriptions for use.

The prescriptive part of the RLP concerns, for the specific landscape areas, the quality objectives, guidelines, and directives aimed at orienting territorial and urban planning and, for the landscape assets, 88 prescriptions for their use, protection, and valorisation. Municipalities conform their urban planning instruments within two years from the entry into force of the RLP. While waiting for the adaptation of the municipal planning instruments, different construction interventions are allowed (i.e. new realization and extension of existing buildings, subject to landscape authorization and to specific prescriptions). In the coastal areas are considered admissible, for example, interventions for productive, residential, or mixed use and actions of urban regeneration in areas already identified by the urban planning instruments in force at the time of the adoption of the RLP or started before. Specific prescriptions for each type of intervention concern, in principle, the proper integration in the landscape and in respect to the coastline, the application of measures for the landscape impact mitigation, energy efficiency and structural upgrading of existing buildings, the recovery of historical and traditional architectures, the protection of natural continuity and integrity of the coastal strip, the preservation of native plant species.

The plan management is assigned to different types of instruments: "agreements", to regulate the joint development of activities of common interest in relation to the implementation of the RLP, including the adjustment of urban planning tools or the conservation and enhancement of landscapes; "river contracts", for the environmental and landscape rehabilitation of the territory; "integrated landscape projects", aimed at implementing the strategic part of the RLP, the requalification of compromised and degraded areas, as well as for interventions to recover landscape values, for example the recovery of uncultivated or abandoned land for agricultural use; "incentives", which promote the conclusion of agreements, contracts and projects through the allocation of adequate public resources.

\subsection{Discussions}

The process of elaboration of landscape plans in Italy is difficult in terms of time and resources, as demonstrated by the limited number of regions that have achieved the goal of adopting a landscape plan in accordance with the Urbani Code, covering the whole regional territory. There are many reasons for this, but they can certainly be linked to the lack of institutional collaboration between central and regional authorities and to the lack of effectiveness of participatory activities in interpreting the real idea of landscape referred to in the ELC.

The collaboration between the $\mathrm{MiC}$ and the Region, in the joint drafting of the landscape plan, often appears conflicting and sometimes leads to unilateral decisions that weaken the process of co-planning and undermine the sustainability of choices. The extreme bureaucratization of the procedure results in a system 
of constraints imposed from the top, not shared by the same regional administration and therefore, even less, by the communities. In few cases, when the plan has been approved, difficulties have emerged in the effective implementation phase, which involves the acceptance of guidelines and requirements by local communities, into urban and territorial planning instruments.

It is not possible to define a clear overview of the progress status of the process of plan revision in the different regions, due to the lack of updated data or to the recent approval of the landscape instrument, which does not allow to evaluate the effects yet. If we consider some plans approved a long time ago, such as the case of the Sardinian RLP of 2006, the process of adaptation is going very slowly. At present there are only 24 Sardinian municipalities that have updated the general plan, of which only 19 are entirely in the coastal area, which means that they must do so. More than $80 \%$ of the municipalities have not respected the deadlines established by law, also thanks to the absence of sanctions or penalties for non-compliant administrations. The same can be said for Apulia, where just 17 municipalities out of 258 have a plan adapted to the RLTP. Further nine municipalities are finalizing the procedure and eight municipalities have in progress the preliminary investigation for the adaptation of their urban planning instruments to the PPTR.

The transitory regulation, which is in force while waiting for the adaptation of urban planning tools to the landscape plan, is sometimes particularly restrictive and emphasizes the perception of landscape policies as a constraint and limitation to territorial and socio-economic development. This makes it more difficult for communities and local administrations to share their choices, as they claim their own decisionmaking autonomy in the conformation of land uses.

\section{CONCLUSIONS}

We are aware that the proposed reflections do not reach an exhaustiveness of the emerging problems. However, we believed it necessary to put forward some considerations that will help future evaluations and progress in assessing the integration between the regional landscape dimension and the local landscape dimension with the intent of highlighting the operational models of local plans at the current level.

In Italy, the landscape plan has a fundamental role in promoting alternative models of local development, based on the recognition and enhancement of landscape and cultural heritage (Magnaghi, 2000; Poli, 2020). A new idea of landscape is widespread, dynamic, and pervasive, focused on the specificity of places and on the co-evolutionary relationship between the territory and the communities that live there (Magnaghi, 2020; Colavitti, 2020). The complex activity of interpretation and representation of the landscape requires the activation of a constant dialogue between the inhabitants and the different institutional levels involved, from the $\mathrm{MiC}$ to the local authorities. This is a critical point in the elaboration of landscape plans and in the adaptation of local planning instruments.

In addition, there is a risk that the plan might adopt an excessively inclusive idea of landscape and a consequent all-encompassing approach, worsening the inter-institutional conflict that makes difficult to transfer the objectives of the landscape plan to the local scale. The landscape plan is sometimes broadly descriptive but not very incisive in formulating clear and applicable rules for the use and transformation of the territory. As underlined by the case of Friuli Venezia Giulia, the descriptive and cognitive part should certainly capture the complexity and the interrelations of several factors that affect the territory, but the preceptive nature of the plan must address only those aspects that can be legitimately managed by the landscape instrument, in line with the normative disposition. Moreover, the landscape plan cannot aim, by itself, to go beyond the purely conservative model of static protection to identify methodologies and processes that can direct and manage the territorial transformations over time. The unbalanced application of the Code in the national context often reflects considerable differences in the regional urban planning laws, which sometimes increases the complexity of the adaptation of local instruments. In other words, the landscape plan should guarantee efficacy and clear application in those aspects that are under the competence of landscape planning, instead of regulating aspects that must be governed by territorial and urban planning.

The examined landscape plans are different instruments that suffer the disadvantage of referring to a coherent national legislation, but to very different regional situations (La Riccia, 2017). This condition leads, as a natural consequence, to an anomalous way of intervention on the territory, implementing different systems of protection and valorisation, in terms of values and speed, which do not correspond to the original purpose of the national legislator. This reflects and reveals itself especially in the processes of adapting municipal plans to the RLP, whose relations are weakened, because they are unclear, at the level of their respective competences and also confusing in terms of reciprocal agreements. The critical issue of the adaptation process represents a central topic of discussion because it risks undermining the recognition of values by the communities and the ability to identify solutions aimed at adequate forms of governance.

The landscape plan was designed to organize the landscape transformation following the process of revision of the sub-ordered plans. Then it takes into 
account the specific reflections of local communities in reconsidering their awareness of the local landscape and the construction of knowledge required to preserve their identity values (Banini and Ilovan, 2021). In this way the landscape plan allows the local community to rethink its own identity, including the landscape, by choosing the places to be preserved and protected in local planning. In this context, however, something is not working well and has not worked well so far. In particular, the principles of collaboration on which the agreements between the State and the regions are based (Art. 132 of the Code) are definitely in a critical condition, as well as the principles of collaboration between the regions and the municipalities in pursuing the complex process of adaptation. What about the uncertain relationship between landscape planning and urban-territorial planning?

The topic is not new in the disciplinary debate (Civitarese Matteucci, 2005) and is also linked to the fact that the norms contained in urban plans cannot be in contrast with those of landscape plans. It has been repeatedly underlined how difficult it is to reconcile these elements, for example, the effect of urban planning regulations is different from that of landscape regulations, even if the latter are prevalent.

We believe that landscape norms should be oriented towards general prescriptions that, in the updating process, should guide the assumption of responsibility by municipalities to compose an organic framework of prescriptions that are strengthened through the synthesis of participatory platforms. This way, it would be possible to overcome many of the criticalities that were identified during the season of adaptation, which have produced situations that differ from the original purpose of the normative principles and conflictual contents in urban planning instruments because of the tendency to over-simplify the straight coordination of the landscape instrument.

\section{REFERENCES}

Albrecht L., Barbanente A., Monno V. (2020), Practicing transformative planning. The territory landscape plan as a catalyst for change. City, Territory and Architecture, 7, 1. DOI: 10.1186/s40410-019-0111-2.

Arcidiacono A., Fior M., Pasqui G. (2016), Governare il paesaggio. Sfide per il PPR Lombardo. Territorio, 77(2), 15-24. DOI: 10.3280/TR2016-077003.

Banini T., Ilovan O.-R. (eds., 2021), Representing Place and Territorial Identities in Europe. Discourses, Images, and Practices. Cham, Springer International. ISBN 978-3-030-66766-5.

Bitti S. (2008), Il Piano Paesaggistico della Sardegna: problematiche, sfide e opportunità. Urbanistica Informazioni, 219, 43-45.

Campus E., Ercolini M. (eds., 2011), Progettare il paesaggio per sistemi di relazioni. Osservatorio della 90
Pianificazione Urbanistica e della Qualità del Paesaggio. Strumenti n.1. Olbia, Editrice Taphros. URL: http://www.sardegnaterritorio.it/documenti/6_532_2 0151130091232.pdf. Accessed on 17.05.2021.

Cartei G. F. (2008), Codice dei beni culturali e del paesaggio e Convenzione europea: un raffronto. Aedon n.3. URL: http://www.aedon.mulino.it /archivio/2008/3/cartei.htm. Accessed on 16.02.2021.

Civitarese Matteucci S. (2005), La pianificazione paesaggistica: il coordinamento con gli altri strumenti di pianificazione. Aedon n. 3. URL: http://www.aedon.mulino.it/archivio/2005/3/civitares e.htm. Accessed on 16.02.2021.

Colavitti A. M., Serra S., Usai A. (2018), Locus Amoenus. Pianificare il patrimonio culturale per una nuova geografia dello sviluppo. Firenze, Altralinea Edizioni. ISBN 978-88-98743-87-2.

Colavitti A. M. (2018), Urban Heritage Management. Planning with History. Cham, Springer International. ISBN 978-3-319-72338-9.

Colavitti A. M. (2020), Building the territory of resilience. present and future perspectives of the bioregional experience in Sardinia. In: Fanfani D., Matarán Ruiz A. (eds.), Bioregional Planning and Design: Volume II. Cham, Springer. DOI: https://doi.org/10.1007/978-3-030-46083-9_11.

Ercolini M., Morelli E. (2010), La pianificazione paesaggistica in Sardegna. Ri-Vista. Research for Landscape Architecture, 8(1), 141-147. DOI: 10.13128/RV-17320.

Gisotti M. R. (2018), Il piano paesaggistico alla prova del governo del territorio: verso un modello di pianificazione regionale integrata. CRIOS 16(2), 65-76. DOI: 10.3280/CRIOS2018-016006.

La Riccia L. (2017), The Evolution of Landscape in the Italian Urban Planning Culture. Cham, Springer International. ISBN 9783319573670.

Magnaghi A. (2000), Il progetto locale. Verso la coscienza di luogo. Torino, Bollati Boringhieri. ISBN 9788833921501.

Magnaghi A. (ed., 2016), La pianificazione paesaggistica in Italia: stato dell'arte e innovazioni. Firenze, Firenze University Press. ISBN 978-88-6453371-1. URL: https://www.fupress.com/redir.ashx? RetUrl=3318_10109.pdf. Accessed on 22.03.2021.

Magnaghi A. (2020), Il principio territoriale. Torino, Bollati Boringhieri. ISBN 9788833934884.

Marson A. (ed., 2016), La struttura del paesaggio. Una sperimentazione multidisciplinare per il piano della Toscana. Bari, Laterza. ISBN 885812295X.

Martinelli N., D'Onghia V. (2020), The dichotomy between city and countryside in the Italian experience of Regional Landscape planning, UPLanD. Journal of Urban Planning, Landscape and Environmental Design, 5(1), 141-160. DOI: 10.6092/2531-9906/7140.

Ministero per la Cultura (MiC), Direzione generale belle arti e paesaggio (2020), 
Pianificazione paesaggistica - Quadro sinottico: Aggiornamento dicembre 2020. URL: https:// www.beniculturali.it/pianificazione-e-governo-delterritorio. Accessed on 16.02.2021.

Poli D. (2020) The representation process of local heritage for territorial projects. In: Fanfani D., Matarán Ruiz A. (eds.), Bioregional Planning and Design: Volume II. Cham, Springer. DOI: https://doi.org/10.1007/978-3-030-46083-9_4.

Settis S. (2010), Paesaggio Costituzione Cemento. La battaglia per l'ambiente contro il degrado civile. Torino, Einaudi. ISBN 9788806198718.
Trusiani E. (2015), Territorio, ambiente, paesaggio. Un comune denominatore per il piano paesaggistico. In: Trusiani E. (ed.), Pianificazione paesaggistica. Questioni e contributi di ricerca. Roma, Gangemi editore, 24-39.

Vettori N. (2017), Il piano paesaggistico alla prova. I modelli della Toscana e della Puglia. Aedon n. 1.. URL: http://www.aedon.mulino.it/archivio/ 2017/1/vettori.htm. Accessed on 16.02.2021. 